\title{
Efficacy of nasal continuous positive airway pressure therapy in chronic heart failure: importance of underlying cardiac rhythm
}

John L Kiely, Paul Deegan, Aidan Buckley, Paul Shiels, Brian Maurer, Walter T McNicholas

\begin{abstract}
Background-Some previous reports have indicated beneficial cardiac effects of nasal continuous positive airway pressure (NCPAP) in patients with severe congestive heart failure (CHF), but others have reported deleterious cardiac effects, particularly among patients in atrial fibrillation (AF). The aim of this study was to determine if differences in cardiac rhythm influence the acute cardiac response to NCPAP.

Methods-Eleven consecutive patients with CHF were recruited, six in atrial fibrillation (AF) and five with sinus rhythm (SR). Cardiac index was measured during awake NCPAP application by the thermodilution technique during cardiac catheterisation. NCPAP was applied in a randomised sequence at pressures of 0,5 , and $10 \mathrm{~cm} \mathrm{H}_{2} \mathrm{O}$ with three 30 minute applications separated by 20 minute recovery periods without NCPAP. Results-Significant differences were found between the AF and SR groups for cardiac index responses to NCPAP ( $p=$ 0.004, ANOVA) with a fall in cardiac index in the AF group $(p=0.02)$ and a trend towards an increase in the SR group ( $p=$ $0.10)$. Similar differences were seen between the groups in stroke volume index responses but not in heart rate responses. Changes in systemic vascular resistance were also significantly different between the two groups ( $p<0.005$, ANOVA), rising in the AF group but falling in the SR group.

Conclusions-These data indicate an important effect of underlying cardiac rhythm on the awake haemodynamic effects of NCPAP in patients with CHF.

(Thorax 1998;53:957-962)
\end{abstract}

Keywords: congestive heart failure; continuous positive airway pressure; cardiac rhythm

Congestive heart failure $(\mathrm{CHF})$ is an important cause of morbidity and mortality, and the complication of Cheyne Stokes respiration (CSR) appears to be associated with a particularly poor prognosis. ${ }^{1-3}$ Continuous positive airway pressure (CPAP) has been reported to reduce left ventricular transmural pressure in $\mathrm{CHF}$ with possible beneficial effects on cardiac output. $^{4-6}$ These findings suggest that CPAP may benefit some patients with $\mathrm{CHF}$ and, indeed, several studies have reported benefits from CPAP administered via face mask to some patients with acute pulmonary oedema $\mathrm{a}^{7-10}$ or before cardiac transplantation in patients with severe CHF. ${ }^{11}$ Nasal CPAP has also been reported to improve cardiac function in patients with stable severe CHF who are in sinus rhythm (SR), ${ }^{12}{ }^{13}$ particularly where there is associated sleep disordered breathing. ${ }^{44}$ However, other reports have not found beneficial effects of NCPAP in $\mathrm{CHF}^{15}{ }^{16}$ and, in particular, a previous study from this department ${ }^{15}$ has reported detrimental effects of NCPAP applied during wakefulness among CHF patients in atrial fibrillation (AF). These reports suggest that $\mathrm{AF}$ may be an important factor in determining the haemodynamic response to NCPAP in patients with CHF. This question has important clinical relevance since $\mathrm{AF}$ is a common rhythm disturbance in patients with CHF. Furthermore, sleep apnoea is also common in patients with $\mathrm{CHF}$, either central or obstructive, ${ }^{4}$ and NCPAP may be a potential treatment modality in such patients.

The present study was specifically designed to compare clinical and haemodynamic responses to NCPAP in awake patients with $\mathrm{CHF}$ who were either in SR or AF, and the primary focus was to determine whether there is a different cardiac response to NCPAP between the SR and AF groups. A secondary aim was to obtain further information on patients with $\mathrm{AF}$ using a placebo control and different levels of NCPAP.

\section{Methods}

PATIENT SELECTION

Eleven consecutive patients with severe stable $\mathrm{CHF}$ were recruited from the patient population attending the Cardiology Service at St Vincent's Hospital. Patients fulfilled the following inclusion criteria: age under 75 years, New York Heart Association (NYHA) classification stage III or IV, and left ventricular ejection fractions on echocardiography or multiple gated acquisition (MUGA) radionuclide scanning of less than or equal to $40 \%$. Patients were required to be clinically stable with no recent acute cardiac event (such as myocardial ischaemia, infarction or acute pulmonary oedema) in the preceding month and no change in medications during the seven days before recruitment. Medical treatment included digoxin, loop diuretics, and vasodilators, including angiotensin converting enzyme (ACE) inhibitors and nitrates. Patients with primary valvu- 
lar heart disease including significant tricuspid regurgitation were excluded, as were patients with significant primary pulmonary disease and those unable to tolerate nasal CPAP. All patients had detailed pulmonary function testing (TT Autolink, PK Morgan, Gillingham, UK) and resting arterial blood gas measurements by radial artery puncture.

\section{INVASIVE MONITORING}

Medications likely to affect haemodynamic parameters during the course of the study were withheld on the study day-namely, ACE inhibitors, loop diuretics, nitrate preparations, and calcium channel antagonists. All patients gave fully informed written consent and the protocol received prior approval from the hospital ethics committee.

A $7 \mathrm{Fr}$ gauge, four lumen, flow directed thermodilution catheter (heparin-coated Multiflex TD thermodilution catheter; Abbott Critical Care Systems, Chicago, Illinois, USA) was inserted via the right femoral vein into the pulmonary circulation and positioned in a branch of the pulmonary artery. After one hour's rest baseline readings were recorded and included right atrial pressure (RAP), pulmonary artery pressure (PAP), and pulmonary capillary wedge pressure (PCWP) at end expiration, in addition to heart rate (HR) and systolic (SBP) and diastolic (DBP) blood pressures. Cardiac output (CO) and stroke volume (SV) were measured by the thermodilution technique $^{17}$ using $10 \mathrm{ml}$ of $5 \%$ dextrose solution cooled to $0^{\circ} \mathrm{C}$, taking the mean of five readings. Cardiac index (CI) and stroke volume index (SVI) were calculated from $\mathrm{CO}$ and SV by adjusting for body surface area. Systemic vascular resistance (SVR) and pulmonary vascular resistance (PVR) were also calculated using standard formulae. ${ }^{18}$ Arterial oxygen saturation $\left(\mathrm{SaO}_{2}\right)$ was monitored by pulse oximetry (Biox 3700; Ohmeda, Louisville, Colorado, USA).

NASAL CPAP APPLICATION

Following baseline readings, nasal CPAP (Sullivan APD III ${ }^{\mathrm{TM}}$; ResMed, Sydney, Australia) was applied for 30 minutes using a comfortably fitting nasal mask at three different pressure levels $\left(0,5\right.$, and $\left.10 \mathrm{~cm} \mathrm{H}_{2} \mathrm{O}\right)$ applied in random order according to a computer generated randomisation sequence. Zero pressure was applied by fitting the nasal mask without attaching the connecting tubing. Pressure levels were confirmed using a water manometer attached to the NCPAP mask and the mask fitting was adjusted to prevent air leakage. Measurements were repeated at 30 minutes after which the mask was removed and the subject allowed 20 minutes of recovery, after which the same measurements were again repeated.

Patients were positioned on one pillow at 30 degrees inclination during the course of the study. They were kept awake and under continuous observation by one of us (JK) to maintain mouth occlusion during CPAP appli-

Table 1 Clinical characteristics of study patients

\begin{tabular}{|c|c|c|c|c|c|c|c|c|}
\hline \multirow[b]{2}{*}{ Patient } & \multirow[b]{2}{*}{ Rhythm } & \multicolumn{7}{|c|}{ Patient characteristics } \\
\hline & & Age (years) & Sex & $\begin{array}{l}F E V_{1} / F V C \\
\text { (\% predicted) }\end{array}$ & $\mathrm{PaO}_{2}(\mathrm{kPa})$ & $B S A\left(k g / m^{2}\right)$ & Medications & Aetiology \\
\hline JW & $\mathrm{AF}$ & 64 & M & 95 & 10 & 2.12 & $\mathrm{~A}, \mathrm{LD}, \mathrm{D}$ & DCM \\
\hline $\mathrm{CF}$ & $\mathrm{AF}$ & 69 & M & 96 & 14 & 2.06 & $\mathrm{~A}, \mathrm{LD}, \mathrm{N}, \mathrm{Dz}$ & ICM \\
\hline $\mathrm{RL}$ & $\mathrm{AF}$ & 56 & $M$ & 94 & 11.4 & 2.04 & A, LD, D & $\mathrm{DCM}$ \\
\hline NJ & $\mathrm{AF}$ & 58 & $M$ & 113 & 10.1 & 1.66 & $\mathrm{~A}, \mathrm{LD}, \mathrm{D}$ & DCM \\
\hline SC & $\mathrm{AF}$ & 59 & $M$ & 109 & 11 & 2.03 & $\mathrm{~A}, \mathrm{LD}, \mathrm{D}$ & $\mathrm{DCM}$ \\
\hline MD & $\mathrm{AF}$ & 60 & $M$ & 70 & 10 & 1.99 & $\mathrm{~A}, \mathrm{D}$ & $\mathrm{DCM}$ \\
\hline Mean (SD) & & $61(4.7)$ & & $96.2(15.1)$ & $11.1(1.5)$ & $1.98(0.16)$ & & \\
\hline $\mathrm{LD}$ & SR & 62 & $M$ & 115 & 10.5 & 1.77 & $\mathrm{~A}, \mathrm{LD}, \mathrm{D}, \mathrm{N}$ & ICM \\
\hline $\mathrm{JM}$ & SR & 57 & M & 102 & 15.4 & 1.78 & $\mathrm{~A}, \mathrm{LD}, \mathrm{D}$ & DCM \\
\hline MK & SR & 56 & $\mathrm{~F}$ & 114 & 11.7 & 1.73 & A, LD, D & $\mathrm{ICM}$ \\
\hline CK & SR & 64 & $M$ & 86 & 13 & 1.83 & A, LD & DCM \\
\hline TG & SR & 55 & $M$ & 93 & 11.6 & 1.94 & $\mathrm{~A}, \mathrm{LD}, \mathrm{N}$ & $\mathrm{DCM}$ \\
\hline Mean (SD) & & $58.8(4.0)$ & & $102(12.7)$ & $12.4(1.9)$ & $1.8(0.1)$ & & \\
\hline
\end{tabular}

Rhythm indicates the cardiac rhythm present; $\mathrm{AF}=$ atrial fibrillation; $\mathrm{SR}=$ sinus rhythm; $\mathrm{BSA}=$ body surface area; $\mathrm{PCWP}=$ pulmonary capillary wedge pressure at baseline; $\mathrm{A}=$ angiotensin converting enzyme inhibitor, $\mathrm{LD}=$ loop diuretic, $\mathrm{D}=$ digoxin, $\mathrm{N}=$ oral nitrate, $\mathrm{Dz}=$ diltiazem; $\mathrm{DCM}=$ dilated cardiomyopathy, $\mathrm{ICM}=$ ischaemic cardiomyopathy.

Table 2 Baseline haemodynamic characteristics

\begin{tabular}{|c|c|c|c|c|c|c|c|c|c|c|c|c|}
\hline Patient & Rhythm & $\begin{array}{l}C I \\
\left(l / \mathrm{min} / \mathrm{m}^{2}\right)\end{array}$ & $\begin{array}{l}\text { LVEF } \\
(\%)\end{array}$ & $\begin{array}{l}S V I \\
\left(\mathrm{ml} / \mathrm{m}^{2}\right)\end{array}$ & $\begin{array}{l}H R \\
(b p m)\end{array}$ & $\begin{array}{l}S B P \\
(m m \mathrm{Hg})\end{array}$ & $\begin{array}{l}\mathrm{DBP} \\
(\mathrm{mm} \mathrm{Hg})\end{array}$ & $\begin{array}{l}P A P \\
(m m \mathrm{Hg})\end{array}$ & $\begin{array}{l}P C W P \\
(m m \mathrm{Hg})\end{array}$ & $\begin{array}{l}\text { RAP } \\
(m m \mathrm{Hg})\end{array}$ & $\begin{array}{l}\text { SVR } \\
\left(\text { dyne.s } / \mathrm{cm}^{-5}\right)\end{array}$ & $\begin{array}{l}\text { PVR } \\
\left(\text { dyne.s } / \mathrm{cm}^{-5}\right)\end{array}$ \\
\hline JW & $\mathrm{AF}$ & 2.12 & 21 & 38.2 & 56 & 131 & 76 & 37 & 23 & 9 & 1517 & 297 \\
\hline $\mathrm{CF}$ & $\mathrm{AF}$ & 1.60 & 24 & 36.2 & 44 & 131 & 75 & 30 & 22 & 8 & 2158 & 194 \\
\hline RL & $\mathrm{AF}$ & 2.06 & 20 & 22.8 & 90 & 91 & 70 & 13 & 8 & 1 & 1448 & 171 \\
\hline NJ & $\mathrm{AF}$ & 2.17 & 25 & 35.7 & 61 & 124 & 71 & 13 & 9 & -3 & 2030 & 89 \\
\hline SC & $\mathrm{AF}$ & 2.12 & 20 & 30.7 & 69 & 110 & 75 & 11 & 3 & 1 & 1594 & 149 \\
\hline MD & $\mathrm{AF}$ & 1.86 & 33 & 22.7 & 82 & 125 & 68 & 17 & 8 & 2 & 1838 & 195 \\
\hline Mean (SD) & & $1.99(0.22)$ & $24(5)$ & $31.0(6.9)$ & $67(17)$ & $119(16)$ & $73(3)$ & $20(11)$ & $12(8)$ & $3(5)$ & $1764(290)$ & $182(68)$ \\
\hline CK & SR & 2.68 & 38 & 39.3 & 68 & 155 & 80 & 21 & 11 & 11 & 1578 & 163 \\
\hline LD & SR & 1.58 & 20 & 16.0 & 99 & 97 & 67 & 26 & 17 & 13 & 1829 & 514 \\
\hline JM & SR & 2.92 & 30 & 48.9 & 60 & 158 & 97 & 14 & 7 & 5 & 1728 & 108 \\
\hline MK & SR & 2.20 & 14 & 25.5 & 86 & 150 & 93 & 26 & 12 & -2 & 2400 & 295 \\
\hline TG & SR & 1.91 & 23 & 30.5 & 63 & 105 & 70 & 22 & 29 & 7 & 1614 & 108 \\
\hline Mean (SD) & & $2.26(0.55)$ & $25(9)$ & $32.0(12.6)$ & $75(17)$ & $133(29)$ & $81(13)$ & $22(5)$ & $15(8)$ & $7(6)$ & $1830(334)$ & $238(172)$ \\
\hline
\end{tabular}

$\mathrm{AF}=$ atrial fibrillation; $\mathrm{SR}=$ sinus rhythm; $\mathrm{CI}=$ cardiac index $\mathrm{LVEF}=$ left ventricular ejection fraction; $\mathrm{SVI}=$ stroke volume index; $\mathrm{HR}=$ heart rate; $\mathrm{SBP}=$ systolic blood pressure; $\mathrm{DBP}=$ diastolic blood pressure; $\mathrm{PAP}=$ mean pulmonary artery pressure $\mathrm{PCWP}=$ pulmonary capillary wedge pressure; RAP $=$ mean right atrial pressure; $\mathrm{SVR}=$ systemic vascular resistance; $\mathrm{PVR}=$ peripheral vascular resistance. Values are given as mean (SD). 
Table 3 Mean (SD) changes from baseline to 30 minutes of nasal continuous positive airways pressure (NCPAP)

\begin{tabular}{|c|c|c|c|c|c|}
\hline & & $\mathrm{O} \mathrm{cm} \mathrm{H}_{2} \mathrm{O}$ & $5 \mathrm{~cm} \mathrm{H}_{2} \mathrm{O}$ & $10 \mathrm{~cm} \mathrm{H}_{2} \mathrm{O}$ & $\begin{array}{l}\text { ANOVA (two- } \\
\text { way } \\
\text { interaction) }\end{array}$ \\
\hline \multirow[t]{2}{*}{$\mathrm{CI}\left(1 / \mathrm{min} / \mathrm{m}^{2}\right)$} & $\mathrm{AF}$ & $0.12(0.22)$ & $-0.07(0.22)$ & $-0.23(0.13)$ & \\
\hline & SR & $-0.05(0.14)$ & $0.21(0.25)$ & $0.23(0.32)$ & 0.003 \\
\hline \multirow[t]{2}{*}{$\mathrm{SBP}(\mathrm{mm} \mathrm{Hg})$} & $\mathrm{AF}$ & $(4.1)$ & $(7.1)$ & 7.7 (9.2) & \\
\hline & SR & (3.9) & $0.6 \quad(3.1)$ & $-2.6 \quad(4.2)$ & 0.03 \\
\hline \multirow[t]{2}{*}{$\operatorname{SVI}\left(\mathrm{ml} / \mathrm{m}^{2}\right)$} & $\mathrm{AF}$ & $1.27(5.36)$ & $-2.77(4.91)$ & $-5.35(3.65)$ & \\
\hline & SR & $-0.60(1.62)$ & $2.42(2.85)$ & $3.94(5.45)$ & 0.02 \\
\hline \multirow{2}{*}{ SVR (dyne.s/cm $\mathrm{cm}^{5}$ ) } & $\mathrm{AF}$ & (207) & $(306)$ & (199) & \\
\hline & SR & (354) & -134 & -246 & 0.002 \\
\hline \multirow[t]{2}{*}{$\mathrm{MAP}(\mathrm{mm} \mathrm{Hg})$} & $\mathrm{AF}$ & $1.6(2.8)$ & $2.3(6.3)$ & $2.9(7.6)$ & \\
\hline & SR & $2.3(4.9)$ & $0.9 \quad(2.8)$ & $-2.3(4.1)$ & NS \\
\hline \multirow{2}{*}{$\mathrm{MPAP}(\mathrm{mm} \mathrm{Hg})$} & $\mathrm{AF}$ & $-0.5 \quad(2.9)$ & $-1.8(3.7)$ & $1.8 \quad(2.8)$ & \\
\hline & SR & $0.4 \quad(2.1)$ & $2.4 \quad(1.5)$ & $-0.8 \quad(3.1)$ & NS \\
\hline \multirow[t]{2}{*}{ PCWP (mm Hg) } & $\mathrm{AF}$ & $0.7 \quad(2.3)$ & $1.3(1.8)$ & $2.9(4.9)$ & \\
\hline & SR & $-0.4 \quad(2.9)$ & $1.6(1.5)$ & (1.4) & NS \\
\hline \multirow[t]{2}{*}{ PVR (dyne.s/ $/ \mathrm{cm}^{5}$ ) } & $\mathrm{AF}$ & $-33.1 \quad(35.7)$ & $-56.6(63.8)$ & $0.9 \quad(95.9)$ & \\
\hline & SR & $37.4 \quad(49.1)$ & $4.2(24.6)$ & $-53.7(91.6)$ & NS \\
\hline \multirow[t]{2}{*}{$\mathrm{RAP}(\mathrm{mm} \mathrm{Hg})$} & $\mathrm{AF}$ & $-0.2(1.3)$ & $0.6 \quad(1.0)$ & 2.7 (1.4) & \\
\hline & SR & $0 \quad(0.7)$ & $1.2(0.8)$ & (1.4) & NS \\
\hline
\end{tabular}

Change from time 0 to 30 minutes of NCPAP application at each pressure, according to subgroup. $\mathrm{AF}=$ atrial fibrillation; $\mathrm{SR}=$ sinus rhythm $; \mathrm{CI}=$ cardiac index; $\mathrm{SVI}=$ stroke volume index; $\mathrm{HR}=$ heart rate; $\mathrm{SBP}=$ systolic blood pressure; $\mathrm{MAP}=$ mean blood pressure; $\mathrm{PAP}=$ mean pulmonary artery pressure; $\mathrm{PCWP}=$ pulmonary capillary wedge pressure; $\mathrm{RAP}=$ mean right atrial pressure; SVR $=$ systemic vascular resistance $;$ PVR $=$ peripheral vascular resistance.
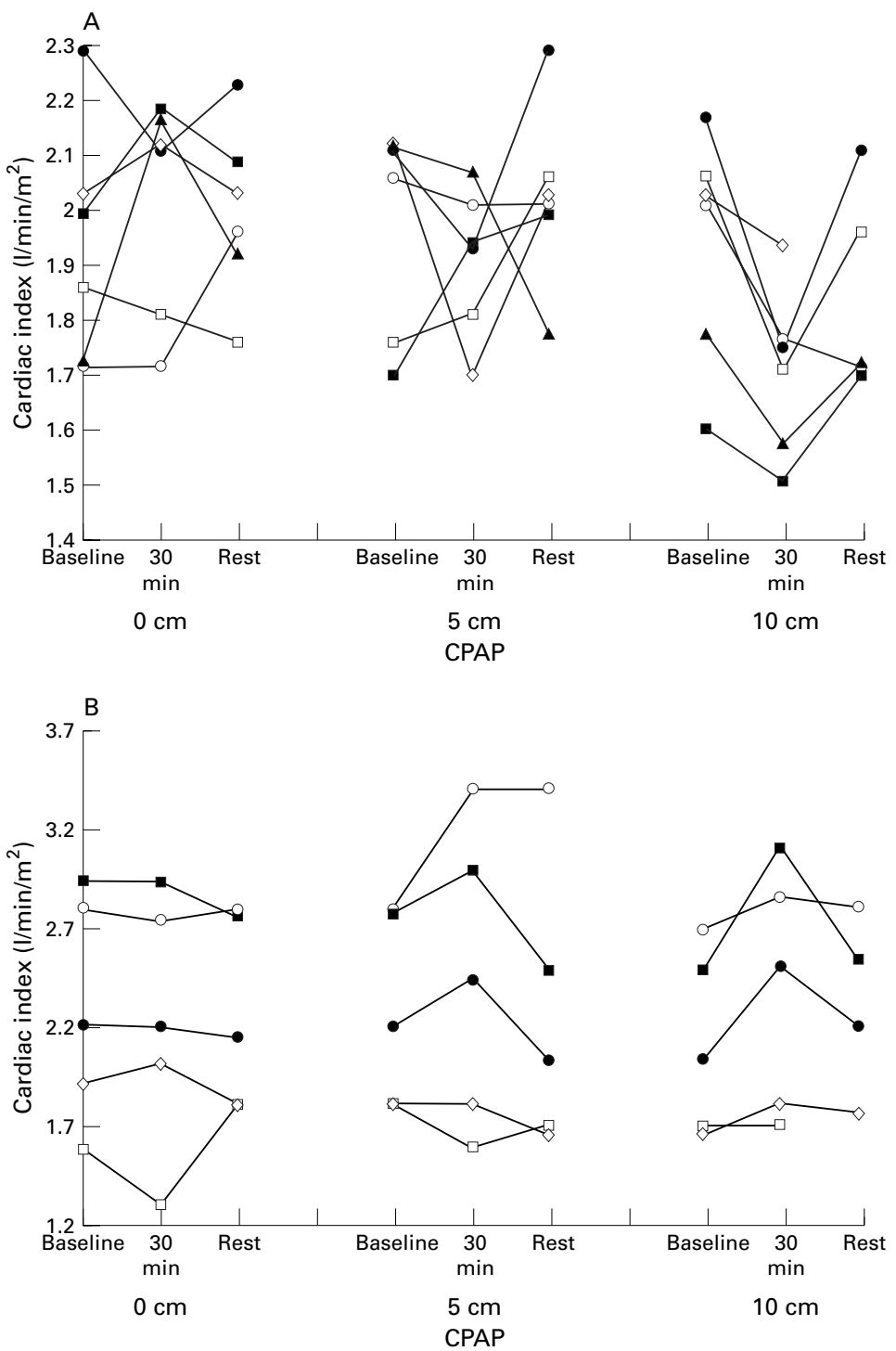

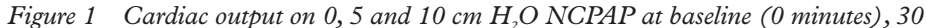
minutes NCPAP and at rest 20 minutes after removing the mask (plotted sequentially on horizontal axis in (A) patients with atrial fibrillation and $(B)$ patients in sinus rhythm. cation in order to ensure maximum transmission of mask pressure to the thorax. ${ }^{19}$

STATISTICAL ANALYSIS

The baseline clinical characteristics and baseline haemodynamic measurements of the two groups of patients (AF and SR) were compared using the Mann-Whitney U test. Between group responses to the effects of the three NCPAP levels were compared by analysis of variance (ANOVA) for repeated measures between groups (two way interaction) and Friedman ANOVA within groups, where appropriate. Post hoc analysis was performed using the Student-Neuman-Keuls (SNK) test. All analyses were performed with a statistical package (Statistica for Windows version 4.5, StatSoft, Tulsa, Oklahoma, USA). A p value of $<0.05$ was considered to be statistically significant. Data are presented as mean (SD).

\section{Results}

The baseline characteristics of the total population of 11 patients are reported in tables 1 and 2 and show no significant differences between the AF and SR groups in anthropometric or baseline haemodynamic measurements. Medical therapy included digoxin, loop diuretics, and vasodilators, including angiotensin converting enzyme (ACE) inhibitors and nitrates, and were broadly similar, although more patients with $\mathrm{AF}$ were taking digoxin. Table 3 details the cardiovascular effects of NCPAP in the two groups and are expressed as the difference between the baseline reading and the value at 30 minutes of continuous NCPAP application at each pressure level applied.

The differences between the two groups in CI responses to NCPAP application were highly significant ( $p=0.004$ by ANOVA) and post hoc analysis by the SNK test confirmed a significant difference $(\mathrm{p}=0.007)$ in CI response at $10 \mathrm{~cm} \mathrm{H}_{2} \mathrm{O}$ NCPAP between the $\mathrm{AF}$ and $\mathrm{SR}$ groups. These data indicate a significant decrease in $\mathrm{CO}$ and CI among patients with $\mathrm{AF}$ with increasing pressure levels $(\mathrm{p}=0.02)$ but, in patients with SR, a trend towards an increase $(p=0.10)$ was observed. Individual patient data detailing the effects of NCPAP on CI are given in fig 1 . Neither baseline cardiac index nor PCWP predicted the CI response to NCPAP. In particular, analysis of the haemodynamic response to NCPAP on the basis of high ( $\geqslant 12 \mathrm{~mm} \mathrm{Hg}$ ) versus low baseline PCWP did not reveal any significant differences in CI responses either between the groups or within each group compared with placebo, irrespective of cardiac rhythm.

There was also a significant difference in SVI response to NCPAP between the AF and SR groups ( $p=0.01$, ANOVA). Nasal CPAP led to a significant fall in SVI in patients with AF $(\mathrm{p}<0.05)$ but there was a trend towards a rise $(\mathrm{p}=0.08)$ in patients with SR (table 3$)$. No significant differences were seen in HR with increasing pressure levels, either between the $\mathrm{AF}$ and SR groups or within each group.

Changes in SVR with NCPAP were significantly different between the two groups 
( $p<0.005$, ANOVA), rising in the AF group but falling in the SR group, and the change from placebo was significantly different $(p<0.05$, SNK test) for both groups. There was also a significant difference between the AF and SR groups in the responses of SBP to NCPAP $(p<0.05$, ANOVA). Post hoc analysis did not demonstrate within group differences to be statistically significant, although the difference in SBP responses to $10 \mathrm{~cm} \mathrm{H}_{2} \mathrm{O}$ between $\mathrm{AF}$ and $S R$ approached statistical significance $(\mathrm{p}=$ 0.06 ) with SBP tending to rise in the AF group while tending to fall in the SR group.

Using the percentage change in CI from baseline to 30 minutes of $10 \mathrm{~cm} \mathrm{H}_{2} \mathrm{O}$ NCPAP to indicate haemodynamic change, significant positive correlation was found for baseline SBP $(r=0.61, \mathrm{p}<0.05), \mathrm{DBP}(r=0.75, \mathrm{p}<0.01)$ and mean arterial pressure (MAP; $r=0.62$, $\mathrm{p}<0.05$ ), suggesting that higher baseline blood pressure levels are associated with a greater rise in CI from baseline during NCPAP application. However, no statistical differences were noted between the AF and SR groups for SBP or DBP at baseline.

There were no significant differences in responses between the AF and SR groups in RAP, PAP, PCWP and calculated PVR during NCPAP application (table 3 ). No significant differences were noted in mean PAP, PCWP, or PVR between the two groups or within each group compared with placebo pressure.

\section{Discussion}

The findings of this study indicate that the acute effects of NCPAP on cardiac function while awake are significantly influenced by the presence or absence of AF and may have implications for the role of CPAP in treating patients with severe CHF. These results add considerable new information over and above our previous report ${ }^{15}$ by clearly demonstrating the importance of underlying cardiac rhythm in determining cardiac response to NCPAP, and also by comparing different CPAP pressure levels with a zero pressure placebo control.

These findings confirm our previous observations in a separate group of stable $\mathrm{CHF}$ patients with $\mathrm{AF}^{15}$ that NCPAP reduces $\mathrm{CO}$ in such patients. While we did not find a significant change in CI with NCPAP among patients in SR, perhaps because of the small numbers studied, the trend towards an increase in CI with NCPAP supports the previous reports of Bradley and others. ${ }^{12}{ }^{13}$ However, this was not the aim of the present study, and the patient numbers were sufficient to show a highly significant difference between SR and $\mathrm{AF}$ in cardiac response to NCPAP, which was the principal study aim.

The effects of NCPAP in CHF assume importance because of the high prevalence of sleep disordered breathing in this condition, and the finding that the presence of Cheyne Stokes respiration carries a particularly bad prognosis. ${ }^{1}$ Recent reports ${ }^{4}{ }^{14}$ have documented improved cardiac function in patients with CHF and sleep apnoea with NCPAP therapy, although another study failed to show benefit. ${ }^{16}$ However, the issue of cardiac rhythm as an indicator of response was not examined in these studies. Furthermore, the benefits of nocturnal NCPAP in CHF with obstructive sleep apnoea may in part be indirect, related to relief of the adverse cardiac effects of repetitive Mueller manoeuvres and hypoxaemia associated with obstructive apnoeas by NCPAP. ${ }^{1420}$ While CHF is associated with central apnoea, there is also a predisposition to upper airway obstruction in this condition ${ }^{21}$ which might benefit from NCPAP therapy. We chose to study awake patients in order to assess more accurately the direct effects of NCPAP on cardiac function and minimise the possibility of confounding effects of CPAP on breathing or breathing disorders during sleep.

Our methodology, which is standard for assessing cardiac output and cardiovascular pressures, ${ }^{71012}$ does not allow us to define precisely how NCPAP caused the observed changes in CI in the two groups. In addition to reducing venous return to the right heart, ${ }^{22}$ NCPAP may also induce flattening and leftward shift of the interventricular septum and reduction in left ventricular volume, ${ }^{23}$ with possible adverse effects on left ventricular compliance. ${ }^{24}$ The above mechanisms tend to reduce left ventricular end diastolic volume and thus preload. When contractility is normal, a reduction in preload decreases left ventricular ejection by the Frank-Starling mechanism. As a result, the normal heart is considered to be preload dependent ${ }^{5625}$ and normal subjects experience a fall in CO with NCPAP. ${ }^{13}{ }^{19}$ In contrast, in patients with heart failure $\mathrm{CO}$ appears to be more responsive to changes in afterload as left ventricular contractility is reduced and may be relatively unresponsive to changes in diastolic volume. ${ }^{56}$ NCPAP increases the functional residual capacity of the lung $^{26} 27$ and the increase in lung volume may contribute to an increase in cardiac surface pressure by compressive effects on the cardiac fossa $^{28}$ with a resultant decrease in left ventricular transmural pressure and afterload. ${ }^{29}$ In addition, by reducing upper airway resistance, CPAP could reduce inspiratory pleural pressure swings with consequent effects on left ventricular afterload. It has been claimed that the negative effects of a reduction in preload in patients with CHF may be outweighed by the beneficial effects of a reduction in left ventricular afterload with consequent improvement in CI. ${ }^{5}{ }^{6}$ The reported finding of an increased CI with NCPAP application in patients with SR could therefore be explained by this mechanism.

In contrast, our patients in $\mathrm{AF}$ experienced a fall in CI with NCPAP application which resulted from a change in SVI, not HR. The mechanism of this fall in SVI is unclear since the patients had a similar degree of heart failure as the SR group with no significant difference in medication or haemodynamic variables. However, several possible mechanisms could be considered. First, diastolic filling of the ventricles in the failing heart is significantly augmented by atrial contraction. ${ }^{30}$ This atrial contribution is lost in patients with $\mathrm{AF}$ and could possibly make them more susceptible to 
the deleterious effects of NCPAP on preload. Secondly, in AF the varying heart rate implies that ventricular filling and emptying will vary on a beat-to-beat basis. Overall, this may make patients with AF more susceptible to the effects of reduced preload, with only a proportion of beats benefiting from any reduction in afterload, and the balance may favour a fall in CI. Finally, neurohumoral differences may exist between $\mathrm{AF}$ and $\mathrm{SR}$ patients with CHF. Patients with AF have higher levels of atrial natriuretic peptide (ANP) $)^{31-34}$ which may render them relatively salt and water depleted, and thus more susceptible to the effects of a reduction in preload.

We did not measure intrathoracic pressure directly with an oesophageal balloon for patient comfort and therefore cannot definitively state that the full CPAP pressure was delivered to the intrathoracic cavity. However, Montner and co-workers ${ }^{19}$ have previously shown that the full nasal CPAP pressure is transmitted to the thorax when the mouth is kept closed, as was the case in our patients.

Although our methodology does not allow us to draw definite conclusions, our data are consistent with the notion that the observed changes in SVR and BP with NCPAP represent compensatory vascular responses to the changes in CO, with SVR and BP falling in SR patients in association with increased CI, and rising in $\mathrm{AF}$ patients to compensate for the fall in CI. While it could be argued that the changes in CI might be secondary to the changes in SVR and BP, the mechanism for this occurring is not easily explained and we regard this as most unlikely for several reasons. Firstly, NCPAP produces pressure changes within the thorax and would not be expected to have a direct impact on either SVR or BP. Secondly, we cannot find any plausible reason why NCPAP should have opposite direct effects on either SVR or BP in patients with AF and SR. We also speculate that the significant correlation between baseline blood pressure levels (SBP, DBP and MAP) and the change in CI on $10 \mathrm{~cm} \mathrm{H}_{2} \mathrm{O}$ NCPAP among the overall patient population may indicate that reducing left ventricular afterload from higher levels with NCPAP might have proportionately larger beneficial effects on cardiac performance. However, further prospective studies would be required to confirm these relationships.

The values obtained for RAP, PA pressures, and PCWP do not take into account changes in transmural pressure with NCPAP. However, if mask pressure was subtracted from the observed readings, no significant differences in the responses were found between the SR and AF groups during NCPAP. Some previous studies have suggested that NCPAP is particularly likely to benefit $\mathrm{CHF}$ patients with raised PCWP. ${ }^{12}{ }^{13}$ However, in keeping with other reports ${ }^{1035}$ we found no significant relationship between baseline PCWP and changes in CO with NCPAP application, irrespective of cardiac rhythm.

We recognise from previous reports ${ }^{7-12} 1436$ that specific subgroups of patients with $\mathrm{CHF}$ may benefit from NCPAP. However, the present findings suggest that the presence of AF should make one cautious about considering CPAP as a potential treatment in $\mathrm{CHF}$ patients with AF. We also recognise that our study represents an investigation of the acute haemodynamic effects of NCPAP during wakefulness and caution must be exercised in extrapolating these findings to more long term effects of NCPAP during sleep in such patients. However, the present data do at least indicate that further studies are required to asses the haemodynamic effects of NCPAP during sleep in $\mathrm{CHF}$ patients with $\mathrm{AF}$.

In conclusion, we found a clear effect of underlying cardiac rhythm, SR or AF, on the acute haemodynamic effects of NCPAP in patients with $\mathrm{CHF}$ which could not be explained by other factors. Our data suggest that therapeutic trials of NCPAP in CHF patients with AF should be undertaken with extra caution, with close surveillance of individual patient responses to this treatment.

Dr Kiely is funded through an Irish Health Research Board post-doctoral fellowship. The authors wish to thank the nursing staff of the Cardiac Department for their contribution to this study.

1 Hanly PJ, Zuberi-Khokhar NS. Increased mortality associated with Cheyne-Stokes respiration in patients with congestive heart failure. Am $\mathcal{f}$ Respir Crit Care Med 1996;153:272-6.

2 Andreas S, Hagenah G, Moller C, et al. Cheyne-Stokes respiration and prognosis in congestive heart failure. Am $\mathcal{F}$ Cardiol 1996; 78:1260-4.

3 Quaranta AJ, D'Alonzo GE, Krachman SL. Cheyne-Stokes respiration during sleep in congestive heart failure. Chest 1997;111:467-73.

4 Naughton MT, Liu PP, Bernard DC, et al. Treatment of congestive heart failure and Cheyne-Stokes respiration during sleep by continuous positive airway pressure. Am $\mathcal{F}$ Respir Crit Care Med 1995;151:92-7.

5 Pinsky MR, Summer WR, Wise RA, et al. Augmentation of cardiac function by elevation of intrathoracic pressure. $\mathcal{F}$ Appl Physiol 1983;54:950-5.

6 Pinsky MR, Matuschak GM, Klain M. Determinants of cardiac augmentation by elevations in intrathoracic pressure. F Appl Physiol 1985;58:1189-98.

7 Grace MP, Greenbaum DM. Cardiac performance in response to PEEP in patients with cardiac dysfunction. Crit Care Med 1982;10:358-60.

8 Rasanen J, Heikkila J, Downs J, et al. Continuous positive airway pressure by face mask in acute cardiogenic pulmonary edema. Am 7 Cardiol 1985;55:296-300

9 Bersten AD, Holt AW, Vedig AE, et al. Treatment of severe cardiogenic pulmonary edema with continuous positive airway pressure delivered by face mask. $N$ Engl $\mathcal{f}$ Med 1991;325:1825-30.

10 Baratz DM, Westbrook PR, Shah PK, et al. Effect of nasal continuous positive airway pressure on cardiac output and oxygen delivery in patients with congestive heart failure. Chest 1992;102:1397-401.

11 Pinsky MR, Marquez J, Martin D, et al. Ventricular assist by cardiac cycle-specific increases in intrathoracic pressure. Chest 1987;91:709-15.

12 Bradley TD, Holloway RM, McLaughlin PR, et al. Cardiac output response to continuous positive airway pressure in congestive heart failure. Am Rev Respir Dis 1992;145:37782 .

13 De Hoyos A, Liu PP, Benard DC, et al. Haemodynamic effects of continuous positive airway pressure in humans with normal and impaired left ventricular function. Clin Sci 1995;88:173-8.

14 Malone S, Liu PP, Holloway R, et al. Obstructive sleep apnoea in patients with dilated cardiomyopathy: effects of continuous positive airway pressure. Lancet 1991;338: $1480-4$

15 Liston R, Deegan PC, McCreery C, et al. Haemodynamic effects of nasal continuous positive airway pressure in severe congestive heart failure. Eur Respir f 1995;8:430-5.

16 Davies RJ, Harrington KJ, Ormerod OJ, et al. Nasal continuous positive airway pressure in chronic heart failure with sleep-disordered breathing. Am Rev Respir Dis 1993;147:630-4.

17 Forrester JS, Ganz W, Diamond G, et al. Thermodilution cardiac output determination with a single flow directed cardiac output determination with a

18 Grossman W, McLaurin LP. Clinical measurement of vascular resistance and assessment of vasodilator drugs. In: Grossman W, ed. Cardiac catheterisation and angiography. Philadelphia, Lea \& Febiger, 1980: 116-23. 
19 Montner PK, Greene ER, Murata GH, et al. Hemodynamic effects of nasal and face mask continuous positive airway pressure. Am 7 Respir Crit Care Med 1994:149:1614-8.

20 Tolle FA, Judy WV, Yu PL, et al. Reduced stroke volume related to pleural pressure in obstructive sleep apnea. $\mathscr{F}$ Appl Physiol 1983;55:1718-24.

21 Bradley TD, Floras JS. Pathophysiologic and therapeutic implications of sleep apnea in congestive heart failure. $\mathcal{F}$ Cardiac Fail 1996;2:223-40.

22 Jardin F, Farcot JC, Gueret P, et al. Echocardiographic evaluation of ventricles during continuous positive airway pressure breathing. ₹ Appl Physiol 1984;56:619-27.

23 Jardin F, Farcot JC, Boisante L, et al. Influence of positive end-expiratory pressure on left ventricular performance. $N$ Engl f Med 1981;304:387-92.

24 Haynes JB, Carson SD, Whitney WP, et al. Positive end-expiratory pressure shifts left ventricular diastolic pressure-area curves. 7 Appl Physiol 1980;48:670-6.

25 Fewell JE, Abendschein DR, Carlson CJ, et al. Continuous positive-pressure ventilation decreases right and left positive-pressure ventilation decreases right and left ventricular $125-32$

26 Harvey LA, Ellis ER. The effect of continuous positive airway pressures on lung volumes in tetraplegic patients. Paraplegia. 1996;34:54-8.

27 Huberfeld SI, Genovese J, Tarasiuk A, et al. Effect of CPAP on pericardial pressure and respiratory system mechanics in pigs. Am f Respir Crit Care Med 1995;152:142-7.

28 Takata M, Robotham JL. Ventricular external constraint by the lung and pericardium during positive end-expiratory pressure. Am Rev Respir Dis 1991;143:872-5.
29 Buda AJ, Pinsky MR, Ingels NB Jr., et al. Effect of intrathoracic pressure on left ventricular performance. $N$ Engl $\mathcal{F}$ Med 1979;301:453-9.

30 Nolan SP, Dixon SH Jr, Fisher RD, et al. The influence of atrial contraction and mitral valve mechanics on ventricular filing. A study of instantaneous mitral valve flow in vivo. Am Heart F 1969;77:784-91.

31 Arakawa $\mathrm{M}$, Miwa $\mathrm{H}$, Noda $\mathrm{T}$, et al. Alternations in atrial natriuretic peptide release after DC cardioversion of non-valvular chronic atrial fibrillation. Eur Heart $\mathcal{f}$ 1995;16:977-85.

32 Wallen $\mathrm{T}$, Landahl S, Hedner $\mathrm{T}$, et al. Atrial peptides, ANP(1-98) and ANP(99-126) in health and disease in an elderly population. Eur Heart f 1993;14:1508-13.

33 Mookherjee S, Anderson G Jr, Smulyan H, et al. Atrial natriuretic peptide response to cardioversion of atrial flutter and fibrillation and role of associated heart failure. Am F Cardiol 1991;67:377-80.

34 Ezaki H, Matsushita S, Shiraki M, et al. Clinical evaluation of the plasma levels of immunoreactive atrial natriuretic peptide in elderly patients with heart diseases. 7 Am Geriatr Soc 1988;36:537-41.

35 Lenique F, Habis M, Lofaso F, et al. Ventilatory and hemodynamic effects of continuous positive airway pressure in left heart failure. Am f Respir Crit Care Med 1997;155:500 5 .

36 Takasaki Y, Orr D, Popkin J, et al. Effect of nasal continuous positive airway pressure on sleep apnea in congestive heart ailure. Am Rev Respir Dis 1989;140:1578-84. 